\title{
Controlled reperfusion is a rose by any other name
}

\author{
Jakob Vinten-Johansen, PhD
}

\author{
From the Division of Cardiothoracic Surgery, Department of Surgery, Emory University, Atlanta, Ga. \\ Disclosures: Author has nothing to disclose with regard to commercial support. \\ Received for publication Sept 1, 2015; accepted for publication Sept 2, 2015; available ahead of print Oct 12, \\ 2015. \\ Address for reprints: Jakob Vinten-Johansen, PhD, Division of Cardiothoracic Surgery, Department of Surgery, \\ Emory University, Atlanta, GA 30365-2225 (E-mail: jvinten@emory.edu). \\ J Thorac Cardiovasc Surg 2015;150:1649-50 \\ 0022-5223/ $\$ 36.00$ \\ Copyright (C 2015 by The American Association for Thoracic Surgery \\ http://dx.doi.org/10.1016/j.jtcvs.2015.09.014
}

Controlled reperfusion covers the broad categories of modified conditions of delivery (temperature, pressure) and composition $(\mathrm{pH}$, antioxidants, citrate-phosphatedextrose) during the initial reperfusion phase. ${ }^{1}$ Algorithms for controlled pressure during surgical and nonsurgical reperfusion have been called by several names, including gentle, gradual, ramped, and staged reperfusion. To some extent, postconditioning, ${ }^{2}$ the sequential starting and stopping of reflow during the opening moments of reperfusion, fits into this category as well. Low-pressure reperfusion (LPR) is yet another mechanical maneuver that fits into the category of controlled conditions of reperfusion and thus represents another rose in the bouquet of controlled reperfusion strategies. Ovize's group has identified an algorithm in which the perfusion pressure during the initial reperfusion phase is transiently reduced. LPR has been associated with postischemic functional recovery, reduction in morphologic injury, and attenuated mitochondrial permeability transition pore opening. Opening of the mitochondrial permeability transition pore may be the switch that determines survival or demise for the cardiomyocytes and may further determine whether that demise is by apoptosis or necrosis. The one assumption heretofore made in the concept of controlled reperfusion is that the maneuver has to be applied immediately at onset of reflow.

The study described in this issue of the Journal by Ferrera and colleagues ${ }^{3}$ tested the hypothesis that LPR protection is retained even if application is delayed, while protection with delayed postconditioning is lost. The basis of this hypothesis is that reperfusion injury develops over time. The findings are intriguing and add to the substantial experimental database that controlling reperfusion conditions is cardioprotective.

The strengths of the study include the following: (1) both postconditioning and controlled reperfusion of some form (gradual or low pressure) are clinically applicable; (2) the isolated rat heart model has well-characterized strengths and limitations (discussed here), cogently described by Ferrera and colleagues ${ }^{3} ;(3)$ the study design has appropriate shams, controls, and comparison groups; (4) Ferrera and

\begin{tabular}{|c|c|c|c|c|}
\hline & \multicolumn{3}{|c|}{ Preclinical Studies } & \multirow{2}{*}{$\begin{array}{l}\text { Clinical } \\
\text { Studies }\end{array}$} \\
\hline & Langendorff & Large Animal & Surgical & \\
\hline Early LPR & Yes & No & No & No \\
\hline Early PostC & Yes & Yes & Yes & Yes \\
\hline Delayed LPR & Yes & No & No & No \\
\hline Delayed PostC & Yes & Yes & No & Yes \\
\hline
\end{tabular}

Studies performed in preclinical models in the progression of the "bench to bedside" translation of LPR and postconditioning.

Central Message

Delayed low-pressure reperfusion is clinically applicable, but must be validated in large animal models of CPB and cardioplegia.

See Article page 1641.

colleagues ${ }^{3}$ have justified with previous data the use of $2 \mathrm{cy}-$ cles of postconditioning rather than the 3 originally used in in vivo studies ${ }^{2}$; and (5) a molecular basis was assessed.

The weaknesses of the study include the following: (1) the isolated crystalloid perfused rat heart model is far removed from human physiology and pathophysiology, as acknowledged by Ferrera and colleagues ${ }^{3}$; (2) in rats, the "reperfusion injury window" is accelerated relative to larger animals and human beings (in which its duration may be up to 24 hours), so the "grace period" offered by delayed LPR, if it exists, may be longer in larger species; (3) the role of the reperfusion injury signaling kinase pathway components may be different in rats than in human beings; and (4) the mechanisms by which protection is retained when LPR is delayed remains undetermined, although delayed activation of the reperfusion injury signaling kinase pathway was somewhat ruled out.

LPR, like other controlled reperfusion strategies, can be applied in the surgical environment. The low-pressure period can be applied while the crossclamp is on by delivering a terminal cardioplegia (with or without potassium) or normal blood perfusion with extracorporeal devices. The perfusionist will likely be in the driver's seat, with coordinating input from the rest of the surgical team.

As with all good studies, the study by Ferrera and colleagues ${ }^{3}$ raises important questions.

With regard to basic science, the following questions arise: (1) Is LPR similar to other forms of controlled reperfusion? (2) Online data suggest that the reperfusion injury signaling kinase pathway (Akt/ERK1/3/PI3-k) is involved in immediate but not delayed LPR, so what other mechanisms can reverse or prevent ongoing injury 
mechanisms? Are there purely mechanical mechanisms, such as alteration in intravascular Starling hydrodynamic forces? (3) Are the effects of delayed postconditioning and LPR additive? (4) Do LPR and delayed LPR attenuate the injurious concentration of reactive oxygen species while retaining signaling reactive oxygen species? (5) Finally, does early and delayed LPR attenuate other injury mechanisms such as inflammation that are known contributors to postsurgical injury?

With regard to Translational Science, the following questions arise: (1) Do the benefits and mechanisms of LPR translate to human beings? A rat is not a pig is not a human being. Obviously, the proof of concept study requires validation in the human "model" of cardiac surgery. (2) Is there an optimal LPR algorithm and duration of grace period that needs to be identified for the human heart undergoing surgery? (3) Does LPR add additional discernable protection to that provided by other cardioprotective strategies? (4) Finally, is LPR beneficial in the human population, with its varied and multiple comorbidities that often thwart other cardioprotective strategies?

In the broadest sense, the study by Ferrera and colleagues $^{3}$ reiterates the importance of the initial reperfusion phase and provides new data suggesting that a grace period may exist if events surrounding surgical reperfusion distract from or prevent its immediate implementation. Moreover, it challenges and may rescue us from the notion of a tight time frame for application of reperfusion interventions that, if missed, provide diminishing returns. It is a young and promising concept; confirmation of cardioprotection by LPR is lacking in more physiologic models and ultimately in human beings undergoing cardiac surgery. LPR can easily be applied by the surgical team, but its benefits independent of the other cardioprotective strategies must be determined. Controlled reperfusion in the broader sense, including LPR, may provide returns that are worthy of a few patient moments invested at the end of the case.

\section{References}

1. Okamoto F, Allen BS, Buckberg GD, Bugyi H, Leaf J. Studies of controlled reperfusion after ischemia. XIV. Reperfusion conditions: importance of ensuring gentle versus sudden reperfusion during relief of coronary occlusion. J Thorac Cardiovasc Surg. 1986;92(3 Pt 2):613-20.

2. Zhao ZQ, Corvera JS, Halkos ME, Kerendi F, Wang NP, Guyton RA, et al. Inhibition of myocardial injury by ischemic postconditioning during reperfusion: comparison with ischemic preconditioning. Am J Physiol Heart Circ Physiol. 2003; 285:H579-88.

3. Ferrera R, Benhabbouche S, Da Silva CC, Alam MR, Ovize M. Delayed low pressure at reperfusion: a new approach for cardioprotection. J Thorac Cardiovasc Surg. 2015;150:1641-8.e1-2. 